\title{
Cefaleia antecedendo paralisia de Bell: Podemos prevenir a paralisia diagnosticando e tratando precocemente?
}

\author{
Headache anticipating Bell's palsy: can we prevent the facial palsy by \\ diagnosing and treating early?
}

\author{
Marcelo Moraes Valença, ${ }^{1,4}$ Luciana Patrízia A. Andrade-Valença, ${ }^{1,4}$ Laryssa Azevedo, \\ Mário Luciano de Mélo Silva Júnior, ${ }^{7}$ Hugo André de Lima Martins, ${ }^{7}$ Amanda Araújo da Silva, ${ }^{7}$ \\ Louana C. Silva, ' Daniella Araújo de Oliveira ${ }^{2}$, Mariana de Carvalho Leal Gouveia, ${ }^{3}$ Sílvio Caldas Neto ${ }^{3}$ \\ 'Unidade Funcional de Neurologia e Neurocirurgia, Departamento de Neuropsiquiatria, \\ ${ }^{2}$ Departamento de Fisioterapia, ${ }^{3}$ Serviço de Otorrinolaringologia, Universidade Federal de Pernambuco, \\ Recife, PE, Brasil, ${ }^{4}$ Serviço de Neurologia e Neurocirurgia, Hospital Esperança, Recife, PE, Brasil \\ Valença MM, Andrade-Valença LP, Azevedo L, Silva Júnior ML, Martins HA, Silva AA, Silva LC, Oliveira DA, \\ Gouveia MC, Caldas Neto S. Cefaleia antecedendo paralisia de Bell: Podemos prevenir a \\ paralisia diagnosticando e tratando precocemente? Headache Medicine. 2013;4(4):105- 11
}

\section{RESUMO}

A paralisia de Bell é uma paralisia facial periférica com alta incidência, que apresenta alguns fatores associados, como a gravidez, diabetes mellitus e hipertensão arterial, além da infecção por alguns subtipos do vírus do herpes, o herpes simples e o herpes zoster sine herpete. Uma característica comum aos pacientes com a paralisia de Bell é a ocorrência da cefaleia dias antes da instalação da paralisia, do mesmo lado e em localização periauricular. Questiona-se, portanto, se é possível a identificação de um padrão característico da dor associada à paralisia e, assim, evitar a progressão da doença ou atenuação do possível desenvolvimento do déficit motor por se iniciar um adequado e imediato tratamento com supressão do processo inflamatório responsável pelo acometimento do nervo facial. Relatamos o caso de um homem de 50 anos de idade, com paralisia facial do lado direito, com dor na região retroauricular ipsilateral "em queimor", sem apresentar piora durante esforço, sem náusea, vômito, foto ou fonofobia. Aos 15 anos de idade, relatou ter apresentado paralisia facial também do lado direito, com forte dor retroauricular, semelhante à recidiva atual. Estamos propondo critérios diagnósticos para a cefaleia retroauricular associada à paralisia facial periférica idiopática.

Palavras-chave: Paralisia de Bell; Cefaleia; Critérios diagnósticos; Dor; Diagnóstico

\section{ABSTRACT}

Bell's palsy is a peripheral facial palsy with high incidence, which has some associated factors such as pregnancy, diabetes mellitus and hypertension, in addition to infection by some subtypes of the herpes virus, i.e. herpes simplex and herpes zoster sine herpete. A common feature of patients with Bell's palsy is the occurrence of ipsilateral headache of periauricular location, days before the onset of the paralysis. It is questionable, therefore, whether it is possible to identify a characteristic pattern of this pain in order to prevent disease progression or mitigate the possible development of motor deficit by initiating appropriate and immediate treatment to suppress the inflammatory process of the facial nerve. We report the case of a 50-year-old man with facial palsy on the right side, with pain in the ipsilateral retroauricular. At the age of 15 he reported a previous episode of facial palsy, also on the right side, with severe retroauricular pain, similar to the current recurrence. We propose diagnostic criteria for the retroauricular headache associated with idiopathic peripheral facial palsy.

Keywords: Facial palsy; Diagnostic criteria; Diagnosis; Headache 


\section{INTRODUÇÃO}

Muitos pacientes com paralisia facial periférica de Bell apresentam cefaleia dias antes da instalação da paralisia. (1) Essa cefaleia ocorre no mesmo lado da paralisia e é de localização periauricular.

A paralisia de Bell é a mais comum neuropatia craniana, ${ }^{(2)} \mathrm{com}$ incidência alta (10-30 indivíduos/ 100,000/ano). Gravidez, diabetes mellitus e hipertensão arterial são descritos como fatores associados. ${ }^{(3-7)}$ Muitas vezes infere-se que infecção pelo herpes simples ${ }^{(8)}$ pode ser o motivo da paralisia e o herpes zoster, na sua forma zoster sine herpete, ${ }^{(9)}$ pode causar paralisia do sétimo nervo craniano (em $6,9 \%$ dos casos) ${ }^{(1)}$ clinicamente semelhante à forma idiopática (de causa indeterminada) da paralisia facial periférica que chamamos de paralisia de Bell. ${ }^{(1,10)}$ Nesse sentido, quando encontramos as lesões cutâneas, caracterizadas por pequenas vesículas, no conduto auditivo externo, pavilhão auricular e palato associadas com paralisia facial periférica, o diagnóstico da síndrome de Ramsay-Hun+ ${ }^{(11,12)}$ causada pelo herpes zoster se torna fácil.

A instalação da paralisia é repentina e não se pode prever o início do quadro paralítico por não haver pródomo, com exceção da dor que, em muitos indivíduos, antecede em vários dias o déficit motor.

Diante desse fato, questionamos se podemos identificar algumas características da dor associada com a paralisia facial periférica, de forma que um diagnóstico precoce e o pronto tratamento com corticoide e antiviral evitaria a progressão da doença, impedindo ou atenuando o possível desenvolvimento do déficit motor por acometimento do nervo facial.

Neste artigo descrevemos o caso de um paciente que apresentou recidiva de uma paralisia facial periférica que foi antecedida por dor intensa na região periauricular ipsilateral.

\section{RELATO DO CASO}

Homem com 50 anos de idade procurou a emergência do Hospital Esperança, Recife, referindo paralisia do lado direito da face. Cinco dias antes da instalação da paralisia surgiu dor na região retroauricular direita "em queimor" (Figura 1), não pulsátil, contínua, cuja intensidade variava entre 4 e $9 / 10$, não piorava no esforço, sem náusea ou vômito, foto ou fonofobia. A dor persistiu até sete dias após o aparecimento da paralisia, mesmo durante o uso do corticoide. Relatou

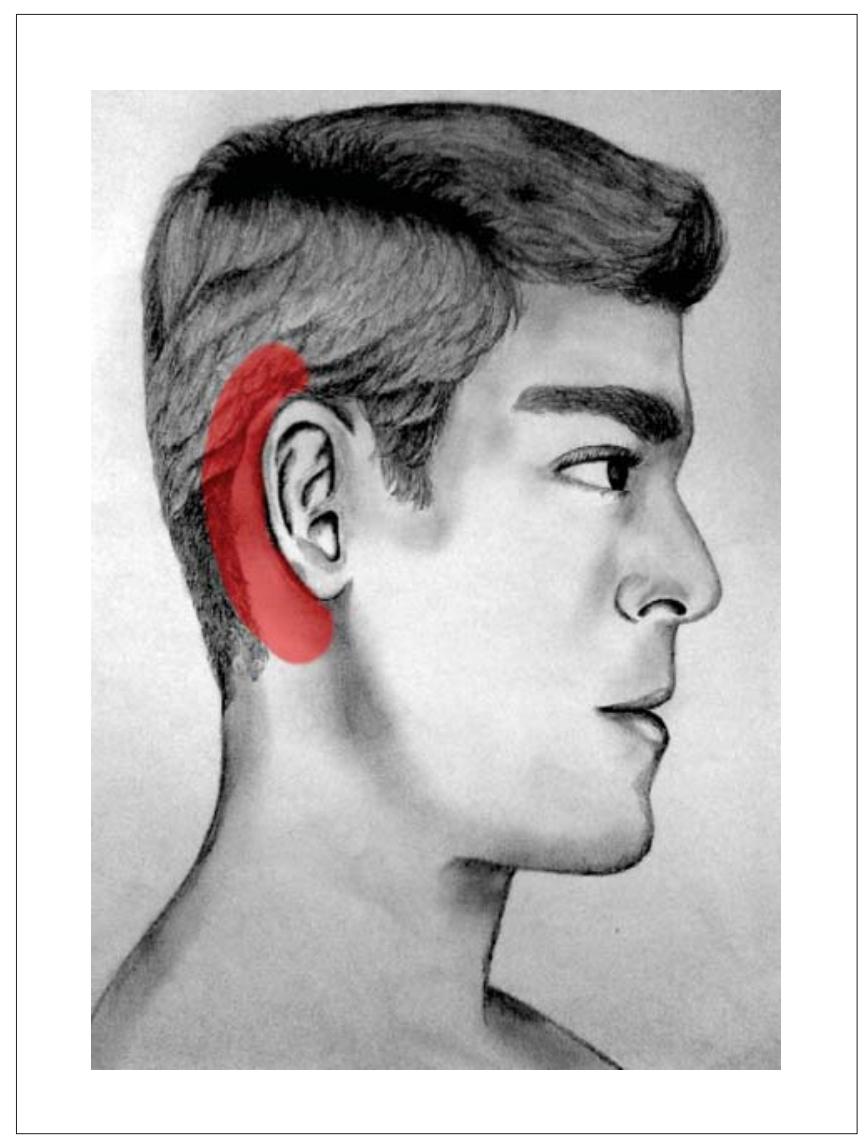

Figura 1. Local da dor (retroauricular) mencionado pelo paciente. Desenho de Laryssa Azevedo

cefaleia do tipo tensional em raras ocasiões. Ao exame observou-se paralisia facial periférica total do lado direito (escala de House-Brackmann grau VI), com preservação do lacrimejamento. Mencionava hiperacusia. Foi medicado com prednisona e aciclovir por 10 dias e recomendada uma proteção do olho direito. Passado de hipertensão arterial leve em uso contínuo de captopril.

O paciente informou que aos 15 anos de idade apresentou paralisia facial periférica também do lado direito, antecedida por dor forte retroauricular semelhante à que ocorreu na recidiva atual. Uma tia sua também apresentou dois episódios de paralisia facial periférica.

Dois meses após o início da paralisia houve recuperação praticamente completa do déficit motor, porém o paciente ainda percebe hiperacusia, ainda que mais leve. No nono dia após a paralisia facial o paciente foi submetido a um exame por ressonância magnética do encéfalo sem contraste que foi considerado normal (Figura 2). 


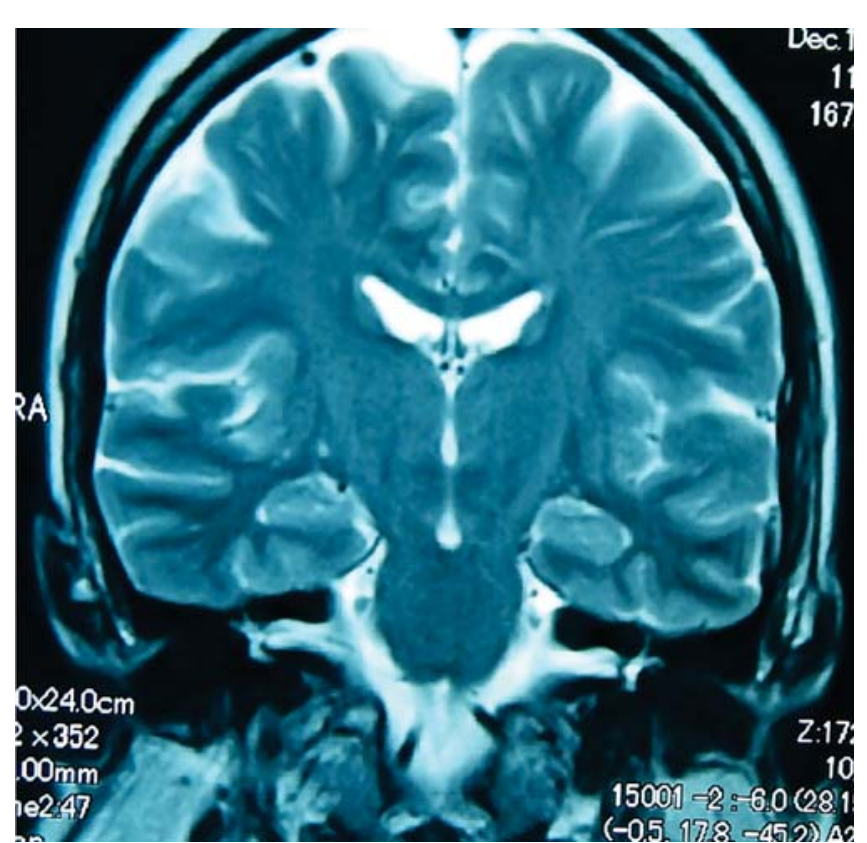

Figura 2. Corte coronal de um exame por ressonância magnética do crânio mostrando os condutos auditivos internos

\section{DISCUSSÃO}

Neste artigo, relatando um caso clínico, estamos lançando a ideia de que seria possível se chegar a um diagnóstico da cefaleia que antecederia a paralisia facial periférica idiopática estudando suas características, e, desta forma, por ser peculiar entre outros tipos de cefaleias teríamos tempo de iniciar uma estratégia terapêutica de proteção do nervo facial, prevenindo um possível dano funcional do nervo facial que ocorreria horas ou dias após.

Em estudo preliminar estudamos retrospectivamente - prontuário de 31 pacientes com paralisia facial periférica idiopática que foram atendidos no Serviço de Eletroneuromigrafia da Unidade Funcional de Neurologia e Neurocirurgia do Hospital das Clínicas da Universidade Federal de Pernambuco. ${ }^{(13)}$ Desses pacientes, $22(71 \%)$ referiam cefaleia antes do surgimento da paralisia e sete $(23 \%)$ afirmaram que a cefaleia surgiu no dia da instalação do déficit motor facial. Nesse grupo, o intervalo entre a dor e o início da paralisia foi de 2,7 $\pm 2,0$ dias (0-7 dias). Dor leve foi referida por 14 pacientes; moderada, por um, e forte, por sete.

Chida e colegas ${ }^{(1)}$ estudaram 58 pacientes com paralisia de Bell e 26 (44,8\%) tinham queixa de dor retroauricular ipsilateral. Em 21 pacientes dos 26 que referiam dor retroauricular a dor precedeu a paralisia 1-12 dias. Em apenas dois pacientes a dor surgiu após a paralisia facial. Baseado em provas sorológicas (anticorpos $\lg G$ e $\lg M$ para vírus vericella-zoster, quatro $(6,9 \%)$ dos 58 pacientes foram considerados como apresentando herpes zoster sine herpete. A dor foi muito mais frequente nos pacientes com zoster sine herpete $(4 / 4,100 \%)$ em relação à paralisia idiopática $(22 / 54$, $40,6 \%$ ) (odds ratio 13,0, IC 95\% 0,67-253,8). Esses autores $^{(1)}$ também observaram que, quando o intervalo entre a dor retroauricular e a paralisia foi maior ou igual a quatro dias, o prognóstico da recuperação da paralisia foi melhor. Eles acreditam que a dor retroauricular deve ser causada por uma neuralgia herpética, inflamação do nervo, incluindo gânglio geniculado e/ou edema do nervo facial com pressão no canal ósseo do facial.

Considerando a fisiopatogenia acima comentada, poderíamos afirmar que a paralisia facial de Bell seria uma síndrome compartimental, i.e. uma elevação da pressão dentro de um espaço anatômico limitado que causaria diminuição significativa da perfusão sanguínea de estruturas que trafegam por ele, como no exemplo o nervo facial.

Perguntamos também se haveria maior suscetibilidade individual quando o espaço no canal ósseo for pequeno em relação ao sétimo nervo (e.g. estenose do canal de Falópio ou do conduto auditivo interno $)^{(12)} \mathrm{com}$ risco maior de dano neural no caso de edema, compressão e hipóxia do nervo facial. Se isso for verdade, alguns pacientes podem apenas apresentar dor retroauricular sem o acometimento paralítico do sétimo nervo craniano quando este espaço for bem maior do que o volume do nervo.

Berg e colaboradores ${ }^{(2)}$ estimam que 33\% a $70 \%$ dos pacientes com paralisa de Bell referiam na fase aguda dor ipsilateral envolvendo as regiões periauricular, da face ou do pescoço. Em seus 826 pacientes com paralisia de Bell, 412 (50\%) apresentaram dor ipsilateral dentro das 72 horas do início da paralisia, e 128/717 (18\%) ainda apresentavam dor ipsilateral após um mês de seguimento ambulatorial.(2) Além disso, 0,8\% (6/717) e 0,9\% (6/ 637) dos pacientes apresentaram a dor tardiamente, um mês e dois meses, respectivamente, após a instalação do déficit. Isso sugere que a dor pode aparecer semanas após o aparecimento da paralisia. Todavia o tratamento com prednisolona ou valacyclovir não influenciou a incidência ou intensidade da dor.

Em outro estudo ${ }^{(14)}$ também não foi observado efeito 


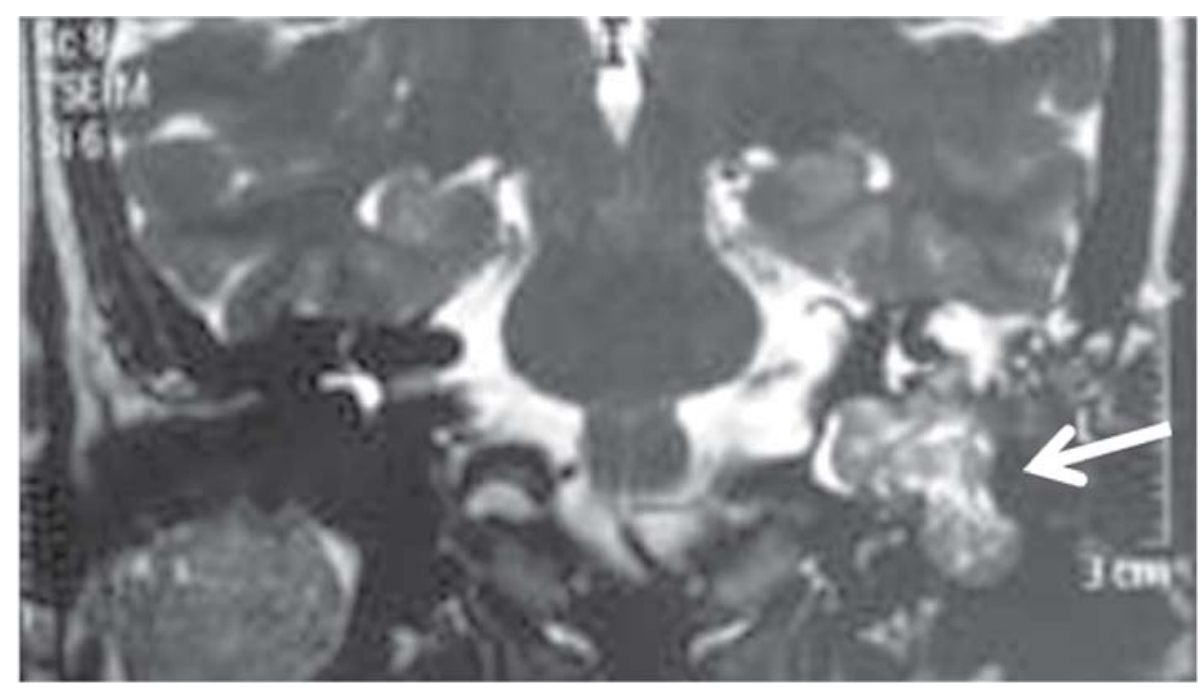

Figura 3. Corte coronal de um exame por ressonância magnética de uma mulher que apresentou paralisia facial periférica associada com dor retroauricular com recuperação espontânea. Seta mostra presença de neoplasia no osso temporal esquerdo

benéfico do tratamento com prednisona sobre a dor. Porém, em estudo(15) não randomizado houve sugestão de benefício do uso do corticoide sobre a dor, pelo fato dos pacientes relatarem retorno da dor com a retirada da prednisona. Pacientes com dor que ocorre entre $\circ 11^{\circ}$ a $17^{\circ}$ dia após a paralisia parecem ter um prognóstico pior em relação à recuperação do déficit motor.

Em estudo por ressonância magnética do segmento no nervo facial que trafega através do conduto auditivo interno distal, gânglio geniculado, tímpano e mastoide, Jun e colegas ${ }^{(16)}$ observaram em um grupo de 44 pacientes com paralisia de Bell, que no lado da paralisia havia um maior grau de captação do contraste pelo gânglio geniculado quando comparado com o lado contralateral, sugerindo que o gânglio geniculado é o segmento do nervo facial mais acometido no processo fisiopatogênico da paralisia de Bell. Esse maior realce do nervo que ocorre após a infusão do gadolínio é entendido como inflamação e edema, pela quebra de barreira. Na interpretação do resultado de um exame por ressonância magnética é importante destacar que, em indivíduos normais, pode haver captação do contraste pelo nervo facial, (17) daí a importância de se comparar com a área contralateral. No entanto, o grau de captação do contraste pelo nervo facial não apresentou correlação com o prognóstico final (duração média do seguimento ambulatorial dos pacientes foi de 13,5 meses). (16) Esses autores concluem, portanto, que a realização de uma ressonância magnética do osso temporal não se faz necessária. Todavia, nós acreditamos que uma inves- tigação por ressonância magnética com uso do gadolínio seja necessária porque não é raro se encontrar casos de paralisia facial periférica de instalação aguda com recuperação completa espontânea e, anos após, na recidiva, se chegar ao diagnóstico de um processo neoplásico como causa. Na Figura 3 mostramos o caso de uma mulher que, aos 25 anos de idade, apresentou paralisia facial periférica esquerda acompanhada por dor retroauricular (iniciada no momento da paralisia cuja duração foi de um dia), havendo recuperação completa da paralisia após três meses. Três anos após houve recidiva da paralisia no mesmo lado, desta vez sem dor e sem recuperação. Na investigação diagnosticou-se um volumoso tumor glômico.

Dor retroauricular foi considerada como fator preditivo de mau prognóstico. ${ }^{(18)}$ Outros indicadores de que pode haver uma recuperação parcial do déficit motor são: idade avançada, pressão arterial sistólica alta, alteração no lacrimejamento, queimor no olho, gosto alterado, grau elevado no House-Brackmann, atraso no início da terapia com corticoide ou o não uso do corticoide. ${ }^{(5,18)}$

A dor retroauricular pode recorrer tempo depois da paralisia de Bell, como nos dois casos descritos por Jacome ${ }^{(19)}$ de mulheres que referiam o ressurgimento de dor durante a menstruação.

\section{Fisiopatogenia da dor}

Partido do pressumposto que os nervi nervorum inervam as bainhas do nervo facial. 
$\mathrm{Han}^{(20)}$ explica o fato da dor na paralisia de Bell se localizar na região periauricular por ser uma dor referida pelo acometimento das bainhas do nervo facial, manifestando-se ao longo do segundo arco branquial com uma distribuição metamérica primária.

O nervo intermédio de Wrisberg contém fibras sensitivas, sensoriais e parassimpáticas (fibras envolvidas na gustação dos dois terços anteriores da língua e fibras secretomotoras das glândulas lacrimal e salivar) e no gânglio geniculado ele se junta à parte motora do nervo facial. As fibras sensitivas trazem informação da orelha externa, mucosa da nasofaringe (palato) e nariz. No gânglio geniculado estão localizados os corpos neuronais das fibras sensitivas do nervo facial, responsáveis pelo meato auditivo externo e grande parte do pavilhão auricular.

\section{Semiologia e nível de lesão do nervo facial}

Do ponto de vista clínico e prático podemos localizar a região do nervo facial onde houve acometimento. A lesão do nervo facial quer no tronco cerebral ou ao longo do seu trajeto periférico pode resultar na paralisia dos movimentos faciais do mesmo lado, e muitas vezes perturbações da sensibilidade gustativa e das funções secretoras. Assim, uma lesão do nervo na saída do forame estilomastoideo provocaria paralisia de todos os movimentos faciais daquele lado (e.g. não se franze a testa, nem se fecha o olho, ou mesmo se mostra os dentes adequadamente). Dessa forma somente haveria déficit motor. ${ }^{(7)}$

Quando a lesão ocorre mais alta, mas distal ao gânglio geniculado, o déficit motor persiste, porém associado a uma alteração da secreção das glândulas salivares sublinguais e submandibulares. Há também hiperacusia e, às vezes, uma perturbação da gustação dos dois terços anteriores da hemilíngua ipsilateral. Explica-se a secreção salivar anormal pela interrupção das fibras parassimpáticas pré-ganglionares provenientes do núcleo salivar superior. A hiperacusia é motivada pela paralisia do músculo estapédio, que tem a função de amortecer oscilações dos ossículos do ouvido médio. ${ }^{(7)}$ Assim sendo, o indivíduo se queixa do timbre desconfortável de sons que antes não incomodavam, como o toque do telefone. Interessante notar que tal fenômeno somente ocorre se o sétimo nervo craniano for lesado na sua periferia, não aparecendo quando a lesão se estabelece no tronco cerebral. Nem sempre a gustação está alterada, pois algu- mas fibras podem tomar um trajeto aberrante e acompanhar o nervo grande petroso. ${ }^{(7)}$ Esse local de acometimento do nervo facial deve ter ocorrido no caso apresentado agora, pois nosso paciente referia hiperacusia e negava distúrbios da gustação e da secreção lacrimal.

Se a lesão do nervo facial se posiciona na porção proximal ao gânglio geniculado, o paciente apresentaria todos os sinais descritos acima e invariavelmente teria perda completa da gustação dos dois terços anteriores da língua. O lacrimejamento (epífora) também estaria alterado no lado da lesão (destruição das fibras parassimpáticas do gânglio esfenopalatino ou pteriopalatino).

Como informação importante anatomofuncional, vale citar que o nervo facial que trafega pelo canal facial emite um ramo (o nervo petroso superficial maior) para o gânglio esfenopalatino logo após o gânglio geniculado. Mais distalmente um novo ramo parte do nervo facial, que se junta ao nervo corda do tímpano, que segue em direção ao músculo estapédio (músculo do estribo).

\section{Recorrência}

Pode haver recorrência da paralisia facial periférica idiopática em $7 \%$ a $15 \%$ dos casos, denominando-se tais casos como forma recorrente, recidivante, "em bascule" ou alternante. ${ }^{(3,21,22)}$ Alguns autores chamam de recidivante quando ocorre no mesmo lado da face, e alternante quando ocorre no lado oposto da face, nas paralisias faciais consecutivas recorrentes. ${ }^{(21)}$

Em estudo nosso anterior ${ }^{(21)}$ envolvendo 190 pacientes, houve 209 episódios de paralisia facial periférica, sendo 16 recorrências $(8,4 \%)$ e, em um dos indivíduos estudados, a paralisia se instalou bilateralmente, havendo recidiva no lado direito 3 anos após o primeiro episódio. $O$ intervalo de tempo entre o primeiro evento e o segundo foi de $45 \pm 50$ meses (mediana de 18 meses, mínimo 3 meses, máximo 13 anos). Em 57\% dos pacientes a recidiva ocorreu até 2 anos após a primeira paralisia. Em dois pacientes houve uma terceira recidiva 5 meses e 6 anos, respectivamente, após a segunda recidiva. Das 18 recorrências $72 \%$ ocorreram no mesmo lado.(21)

A grande maioria das recorrências é da forma idiopática, porém devemos lembrar que recorrências podem acontecer na síndrome de Melkersson Rosenthal, no neurinoma do nervo facial e na otite média, como bem escrevem Li e colaboradores. ${ }^{(23)}$ 
Li e colaboradores ${ }^{(23)}$ afirmam que na recidiva da paralisia facial periférica há uma tendência de haver mais sequelas vinculadas a uma recuperação parcial do déficit neurológico. (24) Por causa do risco de sequela e pela relativa alta chance de haver outra recorrência, alguns autores recomendam a realização de procedimento cirúrgico descompressivo sobre o nervo facial para aqueles indivíduos que apresentaram pelo menos dois episódios da paralisia facial periférica. $(23,25,26)$ Evidência mostra que o risco de haver recorrência aumenta de $15 \%$ no segundo episódio para $50 \%$ no quarto evento. ${ }^{(23,27)}$ Apesar do procedimento continuar a ser realizado até os dias atuais, ${ }^{(23)}$ ainda há controvérsia sobre como realizar a descompressão e acreditamos não haver consenso sobre a indicação de tal procedimento cirúrgico.

\section{Critérios para cefaleia retroauricular associada à paralisia facial periférica}

Com base na informação encontrada na literatura ${ }^{(1,2)}$ entendemos que a dor é estritamente unilateral, contínua por varias horas ou dias, de intensidade variável no mesmo indivíduo (flutua de intensidade ao longo do dia), referida como queimante, surda, não pulsátil, localizada preferentemente na região retroauricular. $\bigcirc$ exame físico da cabeça, incluindo avaliação otológica do paciente, não revela anormalidade. Não há febre.

Diante do exposto acima, tentaremos criar critérios diagnósticos para a cefaleia retroauricular associada à paralisia facial periférica de Bell:

A. Dor retroauricular ou periauricular, que pode se estender para regiões do pescoço e face homolaterais;

B. Dor contínua, porém com variação na intensidade, por mais de oito horas;

C. Sem evidência de processo inflamatório visível periauricular;

D. Nunca sentiu esse tipo de dor antes ou dor com características semelhantes à percebida na ocasião da paralisia facial prévia, se assim for o caso;

E. Não preenche nenhum dos critérios para outro tipo de cefaleia listada no ICDH-3 Beta.

Desta forma, quando um paciente preencher esses critérios diagnósticos gostaríamos de sugerir o uso de corticoide "preventivo" no sentido de atenuar o processo inflamatório e progressão para uma paralisia facial periférica, principalmente naqueles pacientes com história de paralisia facial periférica anterior.

\section{REFERÊNCIAS}

1. Chida K, Okita N, Takase S. Retroauricular pain preceding Bell's palsy: report of three cases and clinical analysis. Tohoku J Exp Med. 2002;197:139-43.

2. Berg T, Axelsson S, Engstrom M, et al. The course of pain in Bell's palsy: treatment with prednisolone and valacyclovir. Otol Neurotol. 2009;30:842-6.

3. Valenca MM, Valenca LP, Lima MC. Idiopathic facial paralysis (Bell's palsy): a study of 180 patients. Arq Neuropsiquiatr. $2001 ; 59: 733-9$. [Article in Portuguese].

4. Hohman MH, Hadlock TA. Etiology, diagnosis, and management of facial palsy: 2000 patients at a facial nerve center. Laryngoscope. 2013 Nov 27.

5. Kondo Y, Moriyama H, Hirai S, Qu N, Itoh M. The relationship between Bell's palsy and morphometric aspects of the facial nerve. Eur Arch Otorhinolaryngol. 2012;269:1691-5.

6. Jenke AC, Stoek LM, Zilbauer M, Wirth S, Borusiak P. Facial palsy: etiology, outcome and management in children. Eur J Paediatr Neurol. 2011 ; 15:209-13.

7. Valença MM, Valença LPAA. Nervo facial: aspectos anatômicos e semiológico. Neurobiologia. 1999;62:77-84.

8. Murakami S, Mizobuchi M, Nakashiro Y, Doi T, Hato N, Yanagihara $\mathrm{N}$. Bell palsy and herpes simplex virus: identification of viral DNA in endoneurial fluid and muscle. Ann Intern Med. 1996; 124:27-30.

9. Lee HY, Kim MG, Park DC, Park MS, Byun JY, Yeo SG. Zoster sine herpete causing facial palsy. Am J Otolaryngol. 2012; 33(5):565-71.

10. Peitersen E. Bell's palsy: the spontaneous course of 2,500 peripheral facial nerve palsies of different etiologies. Acta Otolaryngol Suppl. 2002:(549):4-30.

11. Chodkiewicz HM, Cohen PR, Robinson FW, Rae ML. Ramsay Hunt syndrome revisited. Cutis. 2013;91(4):181-4.

12. Zainine R, Sellami M, Charfeddine A, Beltaief N, Sahtout S, Besbes G. Ramsay Hunt syndrome. Eur Ann Otorhinolaryngol Head Neck Dis. 2012;129(1):22-5.

13. Nascimento MPR, Motta FMA, Oliveira DA, Souza JR, Valença MM, Lins $O G$. Caracterização da cefaléia na paralisia facial periférica de Bell. Migraneas Cefaleias. 2008; 1 1:127-75.

14. Austin JR, Peskind SP, Austin SG, Rice DH. Idiopathic facial nerve paralysis: a randomized double blind controlled study of placebo versus prednisone. Laryngoscope. 1993;103(12):1326-33.

15. Adour KK, Wingerd J, Bell DN, Manning JJ, Hurley JP. Prednisone treatment for idiopathic facial paralysis (Bell's palsy). N Engl J Med 1972;287(25):1268-72.

16. Jun BC, Chang KH, Lee SJ, Park YS. Clinical feasibility of temporal bone magnetic resonance imaging as a prognostic tool in idiopathic acute facial palsy. J Laryngol Otol 2012;126(9):893-6

17. Kinoshita T, Ishii K, Okitsu T, Okudera T, Ogawa T. Facial nerve palsy: evaluation by contrast-enhanced MR imaging. Clin Radiol. $2001 ; 56(11): 926-32$.

18. Shaheen HA, Shalaby NM, El-Shazly N, Abd Allah FA, ShakerE. Acute lower motor neuron facial palsy clinical and quantitative electromyography (QEMG) predictive value. Egypt J Neurol Psychiat Neurosurg. 2007;44:19-36. 
19. Jacome DE. Catamenial synkinetic retroauricular pain. Cephalalgia 2003;23(3):214-7.

20. Han DG. Pain around the ear in Bell's palsy is referred pain of facial nerve origin: the role of nervi nervorum. Med Hypotheses 2010;74(2):235-6.

21. Cauás M, Valença LPAA, Andrade AFA, Martins C, Valença MM. [Recurrent facial palsy]. Revista de Cirurgia e Traumatologia Buco-Maxilo-Facial. 2004;4.

22. Reixach-Casulá R, Beramendi PG, Sanches EP. Paralisia facial periférica recidivante e alternante: registro de um caso com 5 episódios. Arquivos de Neuropsiquiatria. 1982;40:382-84.

23. Li Y, Li Z, Yan C, Hui L. The effect of total facial nerve decompression in preventing further recurrence of idiopathic recurrent facial palsy. Eur Arch Otorhinolaryngol. 2014;4.

24. van Amstel AD, Devriese PP. Clinical experiences with recurrences of Bell's palsy. Arch Otorhinolaryngol 1988;245(5):302-6.

25. Yetiser S, Satar B, Kazkayasi M. Immunologic abnormalities and surgical experiences in recurrent facial nerve paralysis. Otol Neurotol. 2002;23(5):772-8; discussion 778.

26. Doshi J, Irving R. Recurrent facial nerve palsy: the role of surgery. J Laryngol Otol. 2010;124(11):1202-4.

27. Pitts DB, Adour KK, Hilsinger RL, Jr. Recurrent Bell's palsy: analysis of 140 patients. Laryngoscope. 1988;98(5):535-40.

$\overline{\text { Correspondência }}$

Marcelo M. Valença, MD, PhD

mmvalenca@yahoo.com.br

Received: December 5, 2013

Accepted: December 20, 2013 